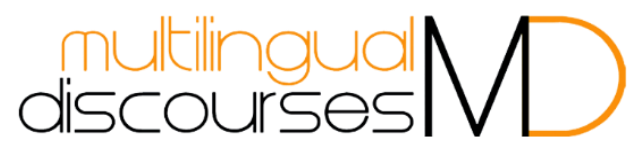

Volume 3.1 / Fall 2016

\title{
Instances of Repair in Oral Exam Settings
}

\author{
Jasmin Hirschberg
}

\begin{abstract}
What started off as a field of interest in studies revolving around Conversation Analysis in the late 1970s (Sacks et al.), has experienced an increasing interest in research on second language learning in institutional settings - repair. Many studies have found that repair is not exclusively targeted at error correction but has been shown to fulfill discourse-related functions as well (e.g. Liebscher and Dailey-O'Cain; Razfar). However, despite its crucial role in institutional settings, assessment situations have been largely neglected in this research. This study aims to fill this gap. It examines how repair is done amongst the instructor and beginner students of German during oral exams. The instances of repair are categorized as self- or other-initiated self-repair (Schegloff et al.). Selfinitiated repair is described following the categories identified by Levelt. Nine beginner learners of German, who have previously shown different levels of learning success, were video-recorded during their oral exams. Using conversational analyst methods, this study aims at identifying 1) What forms of repair occur and which functions they fulfil, and 2) How successful repairs are depending on the learners' level of success. While self-initiated self-repair and error corrections are the most dominant form, the findings also indicate that the oral exam setting elicits economic and pragmatic functions as well and further sharpens the learners' self-perception of their own performance depending on their success level, which influences the ability to spot and repair trouble sources. Pedagogical implications of these findings will be discussed.
\end{abstract}




\section{Introduction}

Repair is a crucial aspect in institutionalized second or foreign language learning settings. The aim of repairing an utterance can be described as the modification of output, an elementary component for language learning, as it directs the speaker's attention to the trouble source, which is necessary for foreign language learning progress (Swain; Gass). Ideally, the learner who has spotted the trouble source correctly identifies the discrepancy between his/her own output and the target form and eventually produces it, which is referred to as uptake.

From a student perspective, repair does not only serve the purpose of correcting errors but can also contribute to ensuring or negotiating comprehensibility of input both meaning- and content-related, which is of high relevance for successful communication on the one hand and for language learning on the other (cf. Vygotski; Krashen; Pica and Washburn; Lightbown).

Regarding both perspectives, repair is understood in very broad terms as "practices for dealing with problems or troubles in speaking, hearing, and understanding the talk in conversation and in other forms of talk in interaction" (Schegloff 207). In research on repair, these practices can either be considered as something "that a learner performs automatically as a result of monitoring and error-detection" (Simpson, Eisenchlas, and Haugh 144) or as a conscious and controlled strategy that serves a social purpose, like defining roles (Liebscher and Dailey-O'Cain) or as an instrument to promote one's own language learning (Rylander).

Regardless of the research focus, repair is commonly referred to as comprising three components: the trouble source, the initiation, and the outcome (Liebscher and Dailey-O'Cain). Accordingly, repair can either be done by the speaker him-/herself (self-repair) or by the listener (other-repair). Self- and other-repair can further be categorized according to the source that triggered or initiated the repair, i.e. self- or other-initiated self- and other-repair (Schegloff et al.). 
For this study, instances of self-repair are exclusively in the focus of interest as the situation of an oral exam does not allow for repair that is done by the instructor. Yet, even within this context, self-repair can be both self- or other-initiated.

Since this study focuses on assessment, the social dichotomy of self versus other is of particular importance. Within the field of sociology, this dichotomy is used to describe social organization and social interaction and it is understood as "two classes of participants in interactive social organizations" (Schegloff et al.). In this study, this dichotomy is realized by the student and the instructor. The relationship between these two is furthermore complementary (Watzlawick), i.e. their interaction is very hierarchical in terms of authority and power. This hierarchy is reinforced by the setting of an oral exam, where the teacher clearly exerts power over the student, which is assumed to play a role in the forms and functions of repair. By augmenting the power differences, the oral exam setting represents a very special setting with regards to repair. Most classrooms now aim at a student-teacher relationship which is characterized by a desire to step away from the teacher being somebody higher up in the hierarchy. Instead, teachers are considered to have more of an assisting and supporting role (Brandl), except for the domain of assessment, which still remains clearly dominated by the teacher. Hence, repair in the classroom is assumed to have different roles than repair in assessment contexts. Although an increasing number of research projects focus on instances of repair in language learning classrooms (Liebscher and DaileyO’Cain; Razfar; Nakamura; Tang; Simpson et al.; Dippold), assessment contexts have been largely left out of the picture, especially oral exam situations. Given the large body of research that focuses on error-repair, it is on the one hand rather surprising that only a small number of studies are set in assessment settings. On the other hand, assessment, be it oral or written, does not allow much room for 'mechanical' repair (i.e. by the teacher) nor for what Smith described as a 'strategic' 
repair, i.e. by the students, which might have a broader purpose due to time constraints in these settings. While teachers mostly respond to error or mistakes mechanically without investing too much thought into the process, students often repair as a result of a monitoring process, i.e. as a result of noticing. This behavior can, over time, turn into a monitoring strategy.

However, since assessment is an obligatory component of institutionalized language teaching and learning, research on the instances of repair and their degree of success occurring in these settings is considered to be crucial and, therefore, the focus of this study. While written forms of assessment are clearly different from every day (oral) classroom discourse, oral exams offer an interesting setting for research on repair since they usually aim at creating an environment that elicits 'naturalistic' conversation but at the same time uses that information as the basis for assessment. In other words, learners are interacting with a conversation partner and assessor at the same time, which becomes particularly interesting in non-standardized exams usually found in secondary or post-secondary situations. Non-standardized tests usually do not require external assessors, which means that students are assessed by their teacher - a condition that augments the power relation between student and teachers, which is usually avoided in classroom interaction. The interest in repair in assessment contexts is strongly driven by pedagogical motives, i.e. the goal is to provide insight and formulate pedagogical implications to improve repair practices for the German as a foreign language classroom, including settings of assessment.

\section{Background}

The most ground-breaking and influential research on repair was done by Schegloff et al. in the 1970s. Focussing on instances of repair in authentic conversational everyday settings, Schegloff and his associates (Sacks and Jefferson) identified different types of repair, i.e. self- and other- 
repair and categorized them even further by describing who dissolves the trouble source (self or other) and where it is located within the conversation, i.e. in the first turn, the transition space between turns or a third turn (Schegloff et al.).

From then on, the categories identified by Schegloff et al. have been studied with different foci, for different languages and within different settings. Schegloff et al. themselves found out that self-repair, in particular self-initiated self-repair (van Lier; Jung), can be observed more frequently in conversational settings than other (-initiated) repair. The opposite turned out to be true within research on repair in classroom settings, where other-initiated self-repair was identified to be the most dominant repair form (McHoul). According to Egbert, two major characteristics of institutionalized settings are responsible for most of the differences between classroom related repair and repair that occurs in everyday conversational settings: 1) In beginner classes of a language, German in this case, the students' do not have access to the full repertoire of potential or appropriate repair requests, especially if under pressure ("Miscommunication" 158), and 2) the requests for repair that are taught in class are not authentic in the sense that they resemble repair requests in non-instructed settings. (160). McHoul found out that teachers initiate repair by cluing, i.e. the teacher leaves 'room' for the student to spot the trouble source "in small steps" instead of pointing to it too explicitly and immediately.

Relevant for this project is a study conducted by Levelt on self-repair and speech. Based on the analysis of over 900 instances of self-repair of Dutch speakers, he identified different categories of self-initiated repair which are used in this study: error repairs, appropriateness repairs, different repairs, and rest repairs. A detailed explanation is provided in the methodology section. While these forms are considered to be overt forms of self-repair, Levelt also observed instances of covert self-repair, i.e. the repair is done in the mind of the speaker before a 
troublesome utterance is actually being made. Consequently, indirect hints such as pauses, repetitions, etc. need to serve as an indicator for this covert process.

Over the years, the number of studies on repair in L2, self-repair in particular, has increased and now, in addition to classroom observation, covers numerous ways of eliciting data such as interviews, storytelling and narration as well as the description of pictures or spaces (Fathman; Lennon; van Hest et al.; Kormos "The Role of Attention"; cf. Smith). In those studies that focus on a conceptualization of repair as mainly driven by language deficiencies, it has been found that the proficiency level of an L2 speaker does seem to be a decisive factor in terms of what is repaired and how. Van Hest et al. identified high proficiency learners as those that repair less frequently than less proficient speakers. Furthermore, "Kormos (1999) found that participants at a higher level of proficiency self-corrected linguistic errors significantly less frequently than learners at the pre-intermediate level" (Smith 87). However, very few studies include individual differences in learning success/performance in their studies but rather look at the learner group as a whole or compare entire groups with each other, e.g. beginner, intermediate, or advanced.

While the interest in grammatically driven research definitely still exists, a considerable number of recent studies try to focus on repair from a perspective that describes the phenomenon not only as a result of the low proficiency of the learners (i.e. the mechanical use of repair) but attributes a series of discourse-related functions to students' self-repair and further considers it to be a valuable source for gaining information about the learner as an entity. Simpson et al. investigated instances of self-repair as observed in learners of Mandarin Chinese and has identified information about the learners that include "monitoring preferences, learning strategies, areas of difficulty, and perceptions about both their proficiency level and the target language" (144). 
In their 2003 article, Liebscher/Dailey-O'Cain conclude that (self-) repair in classroom settings is not only related to linguistic deficiency but it also serves as a role-defining mechanism between teachers and learners. In their conclusion, they state the "initiation of repair ... seems to be governed by a complex set of guidelines that permit both students and the teacher to interact with each other within the boundaries of their respective role as learners and the instructor" (387).

Razfar approaches repair from an ideological perspective and has found out that the vast majority of repairs that he has observed in a high school setting are what he calls "structural," whereas 15\% are "ideological" (412), i.e. he describes these repairs as unnecessary for comprehension. The latter are strongly tied to the role of the teacher and their beliefs about language teaching and learning as well as the language itself. While teachers can exert that kind of power in their repair behaviour, students cannot due to the hierarchical implications of institutional learning environments.

Although many of the above-mentioned studies focus on relationships and dynamics between teachers and students, none of these projects has focused on assessment situations, which can be considered to be an augmentation of the implied hierarchy that students and instructors are part of and which does seem to be an aspect worth studying. One of the very few studies that approximates instances of assessment is a rather early one conducted by Egbert, who investigated instances of repair during oral proficiency interviews. Her findings include that students tend to use forms of repair that are very specific and usually avoid unspecific forms such as "hm?" that leave a lot of room for interpretation. She argues that the avoidance of non-specific requests is not due to a preference of specificity per se but rather related to a high level of language inherent knowledge (German in that case). She explains "interrogatives and partial repeats with question words require a combination of cognitive, linguistic, and interactive skills" ("Miscommunication" 158). While Ebgert did focus on a setting, which is closely related to assessment, she did not 
consider the hierarchical implications nor did she focus on the proficiency level or differences in learning success of the students.

Filipi is one of the only researchers who does investigate instances of repair focusing on learners of Italian. In addition to the frequently identified categories according to Schegloff she has identified two rather new categories, namely "sequences leading to emotional reactions" and "word supply" (119). Research on assessment contexts is so scarce that is not possible to compare findings or draw more general conclusions from it.

In sum, research on repair started off as a purely sociolinguistic phenomenon, predominantly researched in natural conversational settings with second language learners only being peripherally interesting. Later studies have then included language learning classrooms and initially focused on repair in the context of proficiency related issues. These studies were followed by projects that moved aimed at combining both the linguistic and the sociological dimension of repair.

Despite of the numerous studies that have contrasted naturalistic and instructional settings and included several sociolinguistic and even ideological aspects, research that focuses on power hierarchies between students and teachers and in assessment situations in particular are very scarce.

Based on this overview of existing research on repair, the following research questions are at the core of this project: 
- Research question 1: What forms of self- and other-initiated repair occur during an oral exam situation?

- Research question 2: How successful are the repairs, i.e. is mutual understanding finally achieved or are the incorrect forms replaced by the correct ones? Can differences be observed for questions one and two in terms of the degree of a student's language learning success?

\section{Methodology}

\section{Participants}

Nine beginner students of German at a University in Western Canada were video recorded during a midterm oral exam. These nine students were chosen because they demonstrated different degrees of success in terms of language learning (i.e., more successful, moderately successful and less successful). The degree of success is based on classroom performance prior to the oral exam and correspond to the range of the letter grades A (very successful), B (moderately successful) and C (less successful).

\section{Setting and Data Collection}

During the exams, a one-to-one conversation had to be initiated by the student, based on a family photograph. Later on, they were required to ask questions about a family photograph of the instructor. The conversations are 7-10 minutes in length and were video recorded after written consent had been given by the students. The data was transcribed using GATII (Gespraechsanalytisches Transkribieren), developed by Selting et al. This format has been chosen as it is very self-explanatory and can be understood intuitively, even without having the translation chart at hand. Furthermore, it contains all the necessary elements which were relevant for this 
study. Yet, only those elements were included that were actually needed, e.g. pauses, emphasis, change of intonation etc. were only transcribed in relation to repair instances, if needed.

\section{Data Analysis}

The data was analyzed using Conversation Analysis developed by Sacks et al. CA was chosen because repair was established as a phenomenon within CA, which makes it the most suitable approach for this study.

For the description of other- and self-initiated repair, categorizations by Schegloff et al. and Levelt provided the theoretical framework. Not only are those categorizations easily identifiable, they have also served as the framework for numerous previous studies on repair in the past which allows for a comparison between the different findings. In the following, the two frameworks are presented in greater detail and supported by data from the study, if applicable. Typology of Other-Initiated Repair (Schegloff et al.)

(a) The Understanding Check $^{1}$

When this form of other-initiated repair occurs, the speaker indicates that he/she needs a confirmation for what he/she has understood is actually correct. The following example contains such an understanding check:

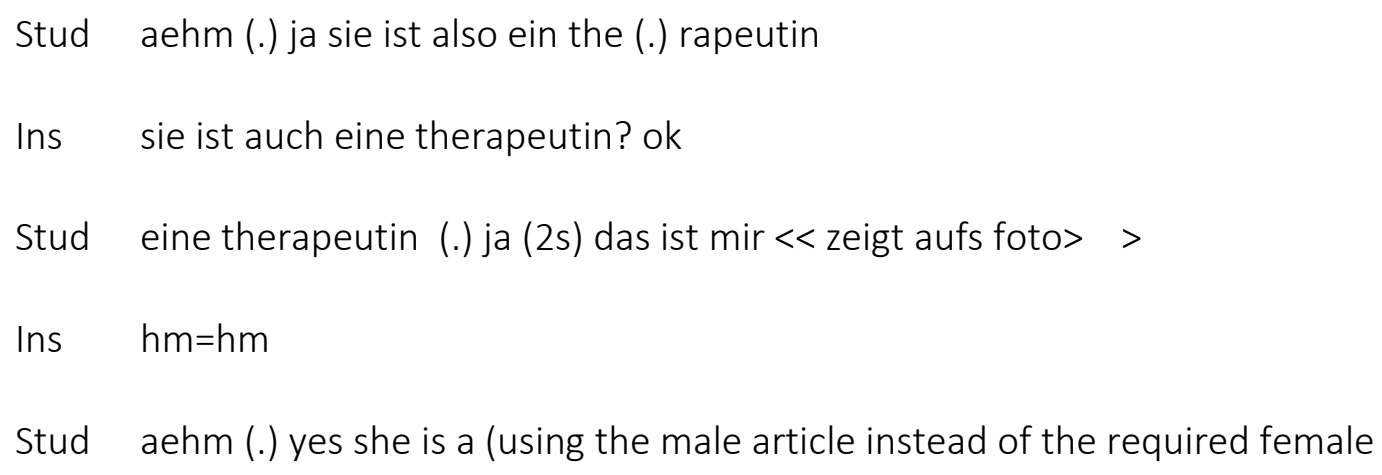

\footnotetext{
${ }^{1}$ Examples that refer to the speakers as Stud and Ins are taken from the sample, those who refer to the speakers with $\mathrm{A}$ and $\mathrm{B}$ are made up for the purpose of exemplifying the repair type. The latter, therefore, do not follow any transcription convention.
} 


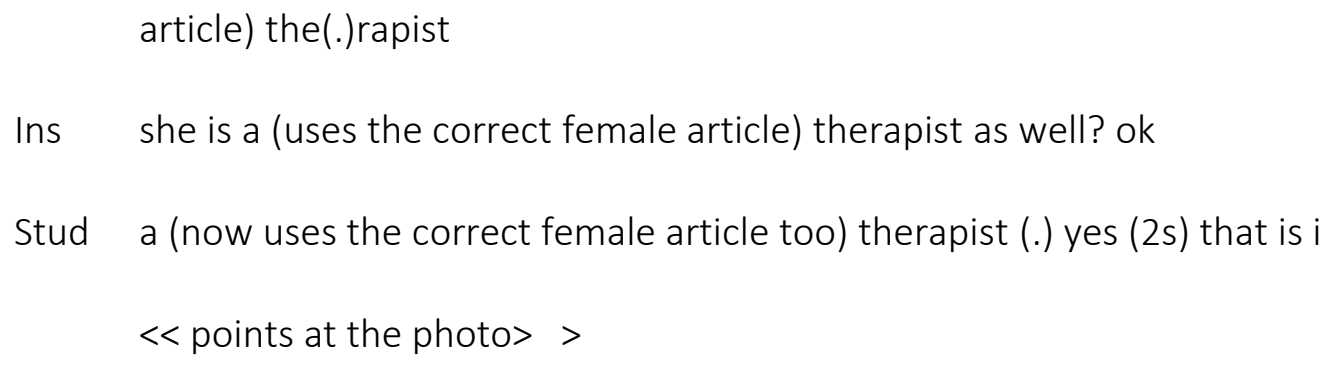

\section{b) The Partial Repeat}

In this form of other-initiated repair only the component of an utterance is repeated which leaves doubts as to whether it has been understood correctly or not:

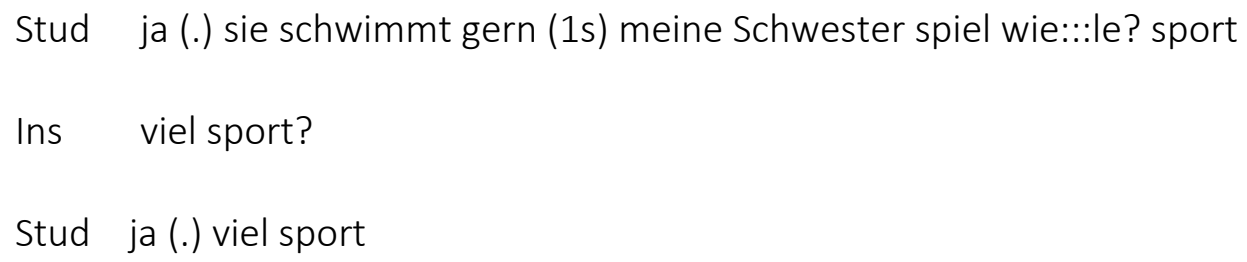

(c) The Partial Repeat with Question Word

This other-initiated repair is very similar to the partial repeat with the exception that a question word is used to further specify the word that has potentially not been understood (correctly).
A: Ich habe mir ein rotes Auto gekauft.
B: Ein rotes was?

A: I bought a red car. 


\section{B: A red what?}

(d) The Interrogative

This form of repair solely consists of an interrogative like what, who, when or how (was, wer, wann, wie):
A: Ich bin um 08:00 Uhr angekommen
B: Wann?
A: I arrived at 08:00 o'clock
$\mathrm{B}: \underline{\text { When? }}$

(e) Non-specified Trouble (+ Body Language)

When the listener cannot spot the trouble source within an utterance, other-initiated repair is nonspecified, i.e. the initiation for repair indicates that the utterance was not understood without explaining what part of the utterance causes trouble.

Furthermore, the video recording also allows for the inclusion of body language and therefore for an analysis of non-verbal other initiated repair, i.e. non-specified trouble:

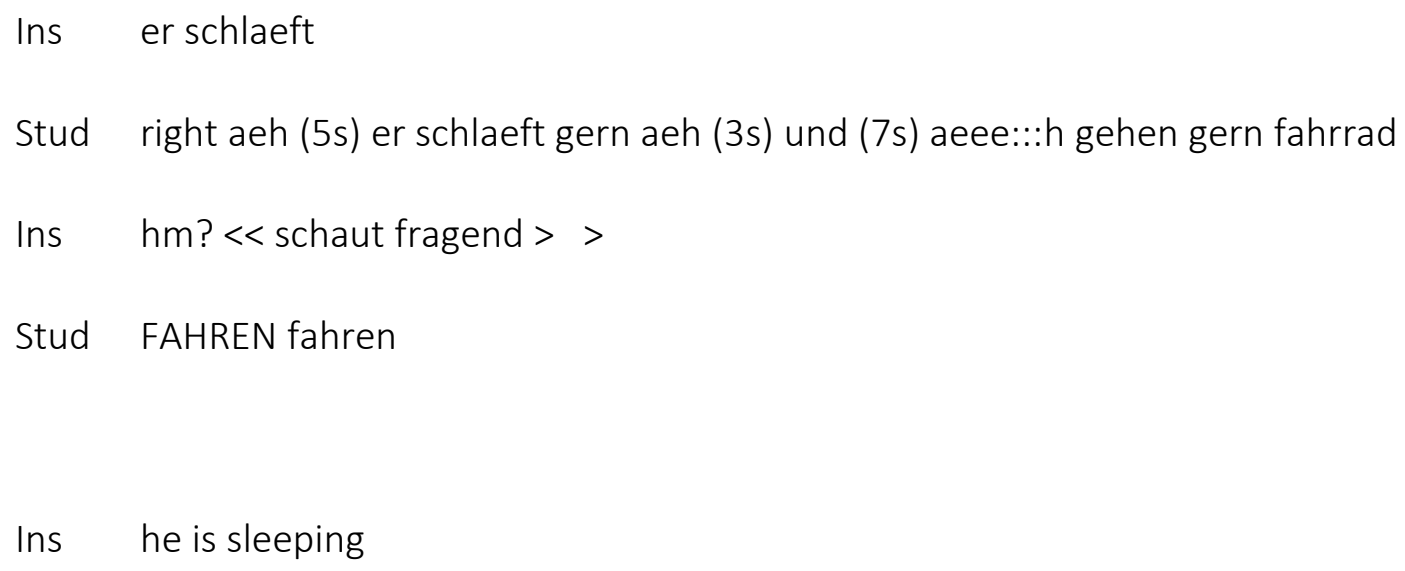




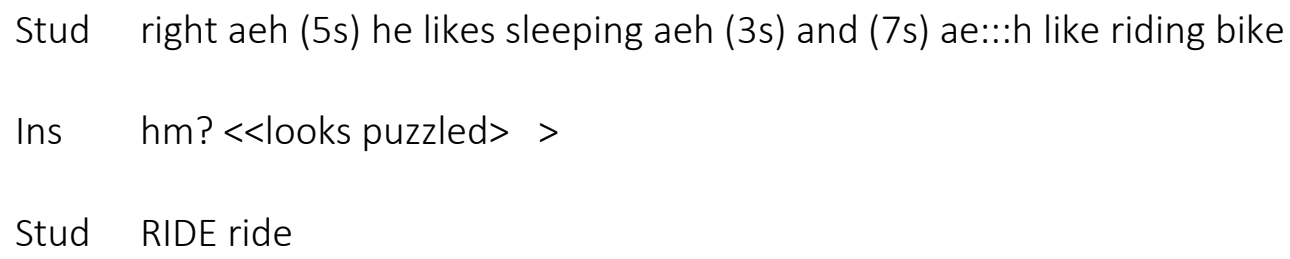

Instances of self-initiated repair are categorized according to Levelt (1983)

Levelt differentiates between overt, i.e. directly observable repairs and covert self-repairs, those that are done before the speaker even utters the trouble source. The subcategories are as follows: Overt Self-Repairs

- Error Repair (E-repair)

Error repairs are done in the case of linguistic inaccuracy. In the following example, the wrong possessive pronoun meine is immediately replaced by the correct one mein

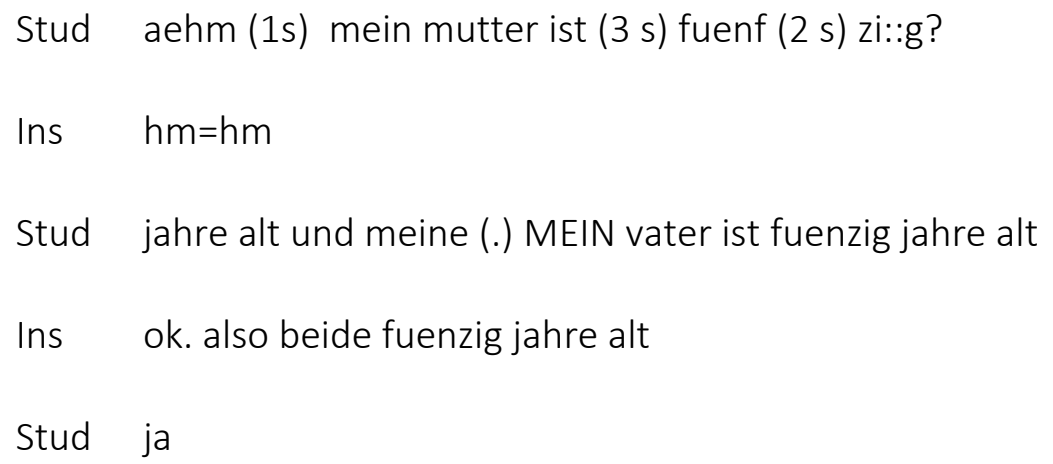


- Appropriateness Repair (A-repair)

Appropriateness repairs are usually content-related and are done when a piece of information that was given is supposed to be specified or modified in a way that is more appropriate for the situation in question:

Stud mein vater ist alt (2s) aehm nein (.) mein vater ist fuenfund aehm (2s) sechzig und meine mutter ist vierundfuenfzig

Stud my father is old (2s) aehm no (.) my father is sixty aehm (2s) five and my mother is fifty four

- Different Repair (D-repair)

According to Levelt, a different repair indicates a switch of topic with respect to the utterance, i.e. the speaker starts to talk about one thing and decides to talk about something else within the same turn:

A: Mein Vater hat am Sonntag ... Nein, ich wollte dir noch von meinem Urlaub erzählen.

A: On Sunday, my father ... no, I meant to tell you about my vacation

\section{- Rest Repair (R-repair)}

Rest repairs are all forms of self-initiated repair that do not fit into any of the categories described above. As the options are various, no further examples are given. 


\section{Covert Self-Repairs}

As has been mentioned before, covert self-repairs take place before a troublesome utterance is formulated. Consequently, the identification of such a covert repair is indirect, i.e. indicators like pauses etc. serve as a way to show that repair takes place.

Due to the problematic nature, which makes it impossible to spot the trouble source (it is even impossible to indicate if it is a repair or a pause that may be a result of trying to think of a particular word etc.) and thereby does not allow for an analysis of the source and pedagogical implications, covert self-repairs will not be included in the analysis and may instead be part of a future research project. The results are presented in the following section.

\section{Results}

Research Question 1: What forms of self- and other-initiated repair occur during an oral exam situation?

Within the 63 minutes and 27 seconds of video recording, 83 instances of self- and other-initiated self-repair could be observed. 21 instances were other-initiated self-repair while 62 instances of self-repair were self-initiated.

\begin{tabular}{|c|c|}
\hline Self-initiated self-repair & Other-initiated self-repair \\
62 & 21 \\
\hline
\end{tabular}


The occurrences of self-initiated self-repair can be divided as follows, based on the categorization by Levelt:

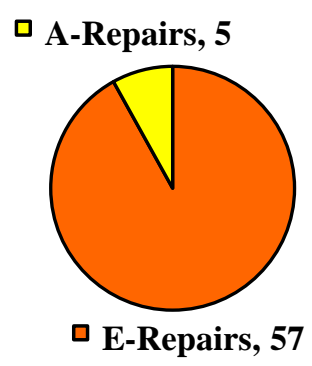

Forms of self-initiated self repair according to Levelt (1983)

As can be seen in the chart, error and appropriateness repairs were the only ones to occur with error repairs clearly forming the most frequently form of self-initiated self-repair. Different and rest repairs could not be observed.

As it will be relevant for the discussion and the results of research question 2, the following chart shows the distribution of the two forms of self-initiated self-repair among the three different student groups, i.e. very successful learners, moderately successful learners and less successful learners. The chart also shows that the moderately successful learners are the ones who repair most frequently: 


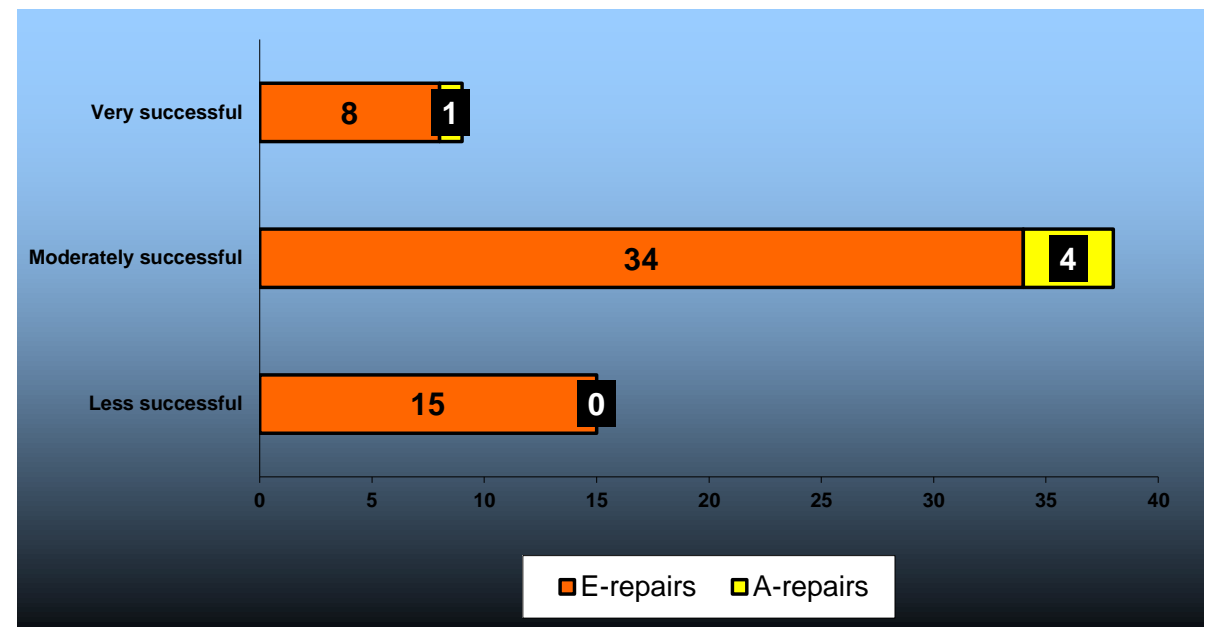

Chart 2: Distribution of self-initiated self-repair amongst learners with a different degree of language learning success

The 21 instances of other-initiated self-repair show the following distribution within the categories formulated by Schegloff et al. Only three out of five categories applied to the students in this study: partial repeat, understanding check and unspecified trouble/body language. The distribution is as follows:

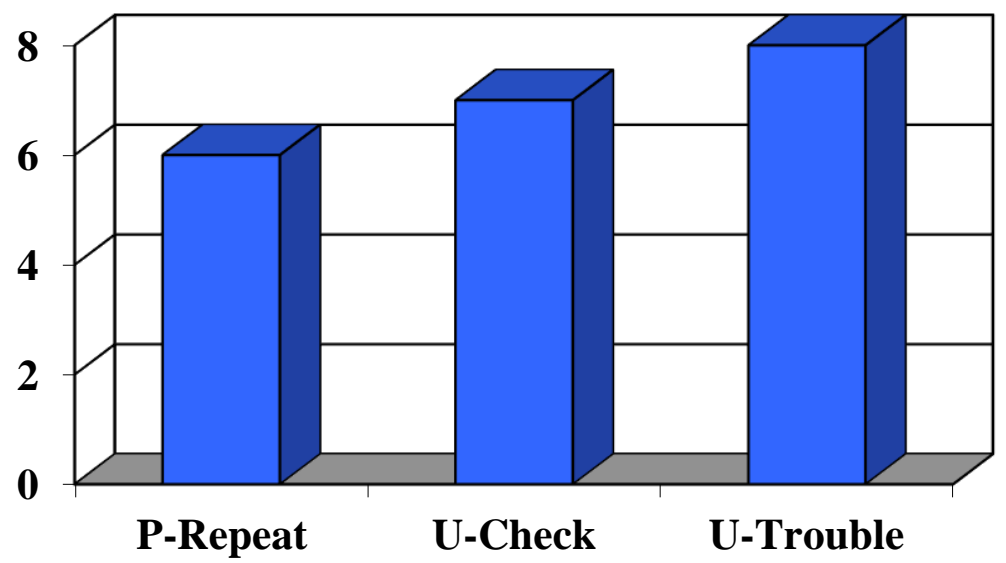

Chart 3: Forms of other-initiated self-repair according to Schegloff et al. (1977) 
The chart shows that the three different types of other-initiated self-repair are distributed rather evenly. For the same reasons as mentioned above, the instances of other-initiated self-repair will also be presented according to their distribution among the three different learner groups:

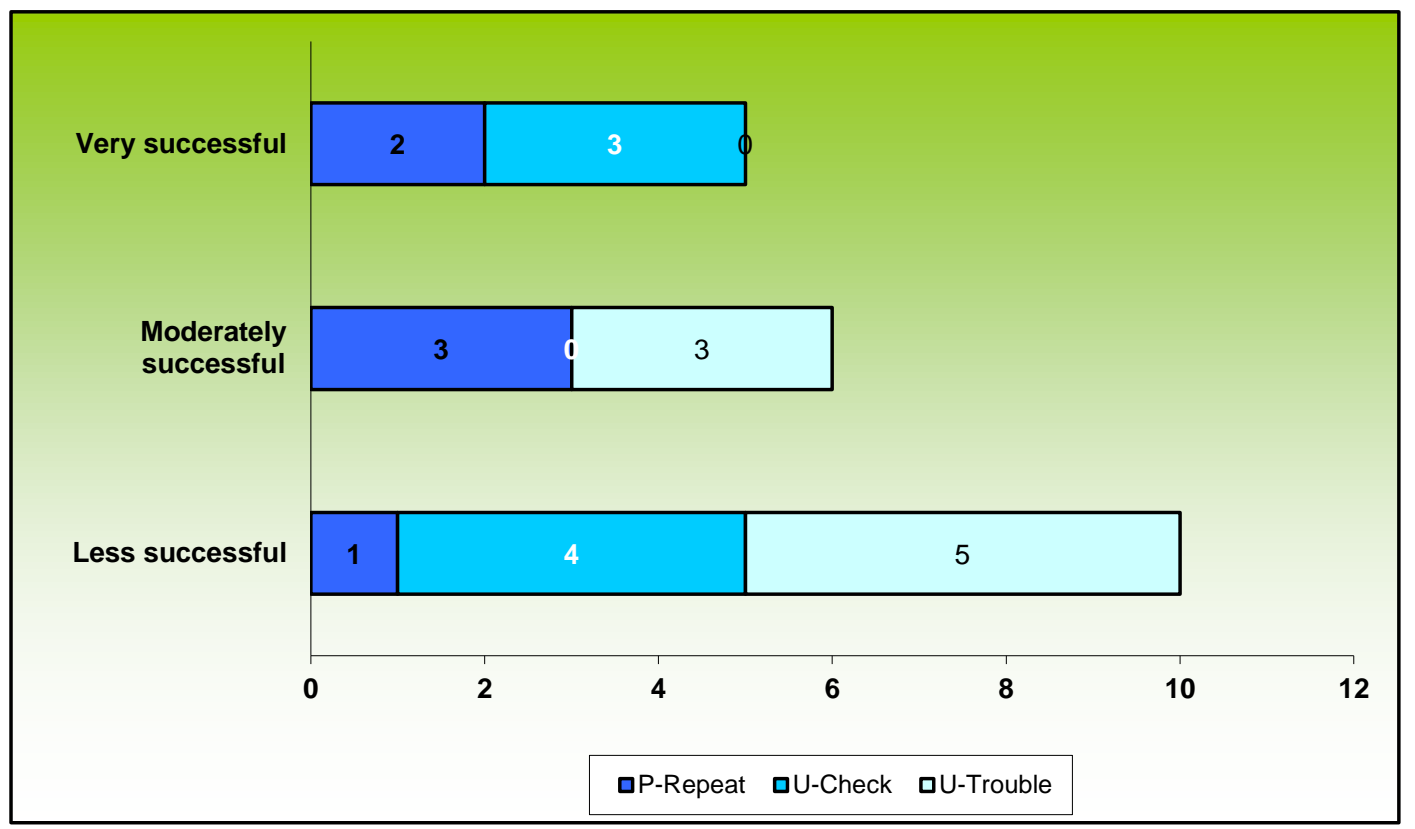

Chart 4: Distribution of other-initiated self-repair amongst learners with a different degree of language learning success

Research Question 2: How successful are the repairs, i.e. is mutual understanding finally achieved or are the incorrect forms replaced by the correct ones? Can differences be observed for questions one and two in terms of the degree of a student's language learning success?

The notion of success was approached differently with respect to the two major forms of selfrepair. While successful self-initiated repair usually means the replacement of a linguistically incorrect form by the correct one, the success of other-initiated repair was measured against the background whether the output was modified afterwards, i.e. after the initiation of the other 
(successful modification) or not. The following examples are stereotypical for each successful type of repair:

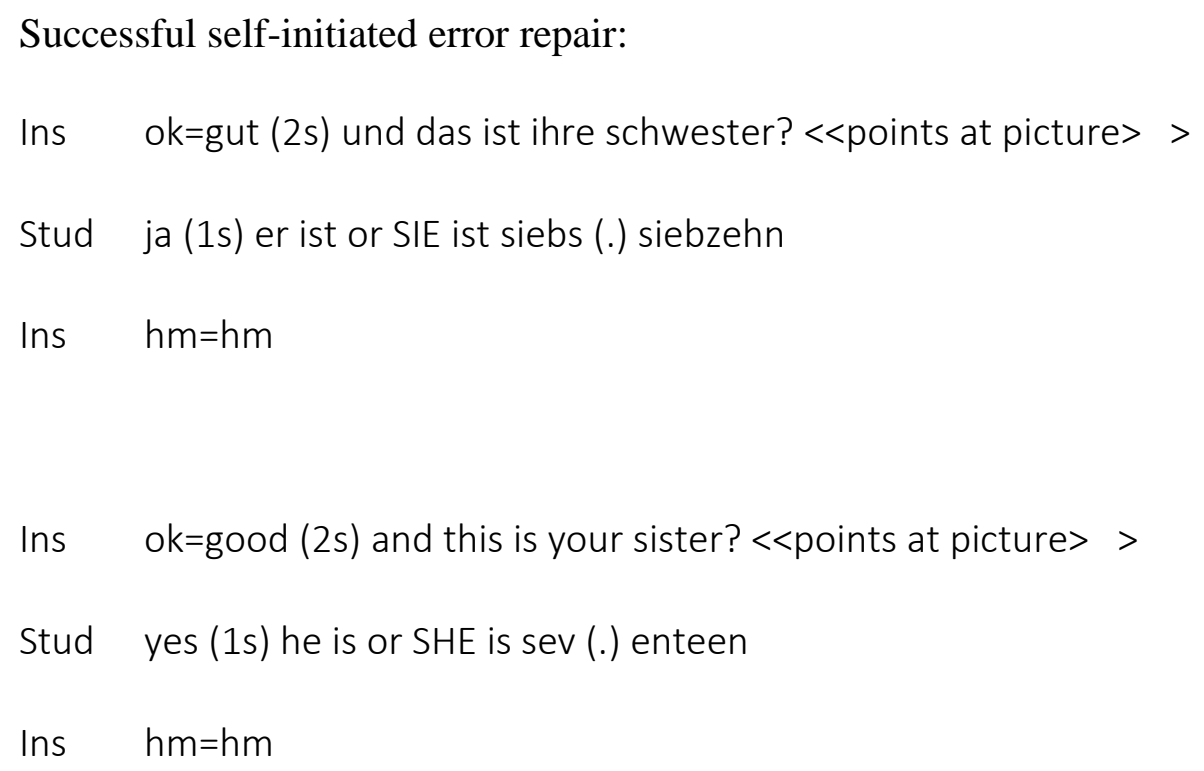

The trouble source, i.e. the wrong personal pronoun is spotted and successfully repaired by replacing it by the correct form.

Successful other-initiated repair:

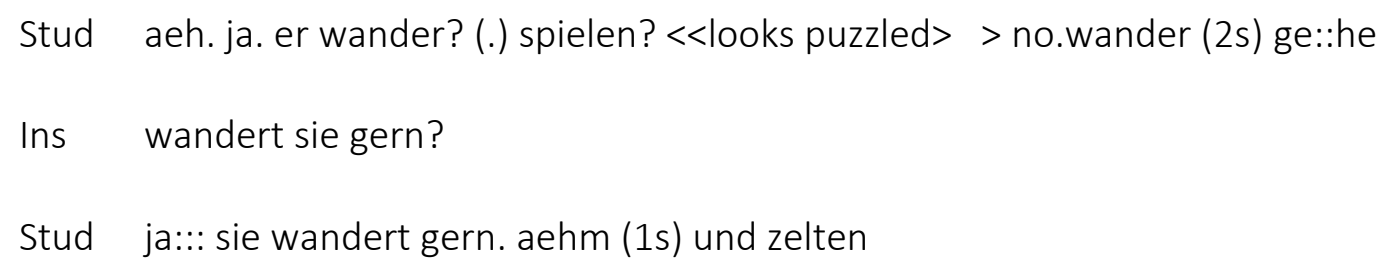


In this example, the student's output is modified, i.e. the initiation by the other was noted and successfully integrated in the student's own sentence, even syntactically adjusted.

Some instances were troublesome as they made it very difficult to decide whether a repair was right or wrong, as the following example is to illustrate:

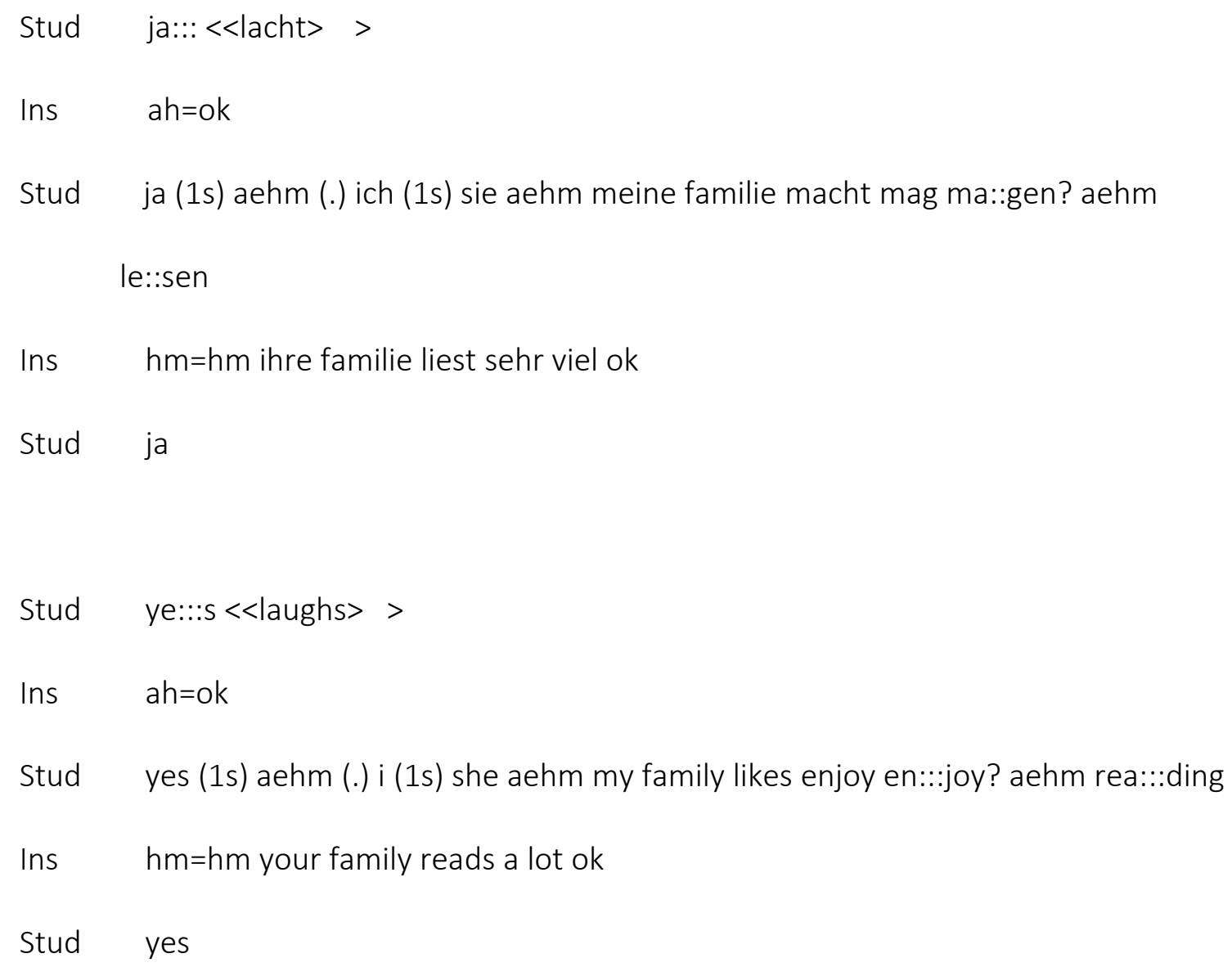

In this example, the trouble source is the choice of the modal verb that goes with lesen, moegen in this case. Macht is the third person singular form of machen and is semantically wrong and cannot be combined with lesen. However, in terms of subject-predicate agreement it is the correct form, as meine familie is third person singular in this case, just as macht. However, for the student it is apparently the semantic level which causes the trouble as she has probably spotted that machen 
and lesen cannot be combined which triggers her repair and results in the choice of the word magen, which is mispronounced and wrongly conjugated but in contrast to machen as the trouble source, she did manage to replace this form by a semantically more adequate one. Strictly speaking, the repair is successful on a purely semantic level. However, as linguistic accuracy is the frame of reference, especially in oral exam situations, those instances were considered to be unsuccessfully repaired.

The first chart indicates the level of success in relation to the form of repair, i.e. selfinitiated vs. other-initiated repair. Non-specified trouble clearly is the most successful form of other-initiated repair, whereas the same is true for a-repairs in the field of self-initiated repairs.

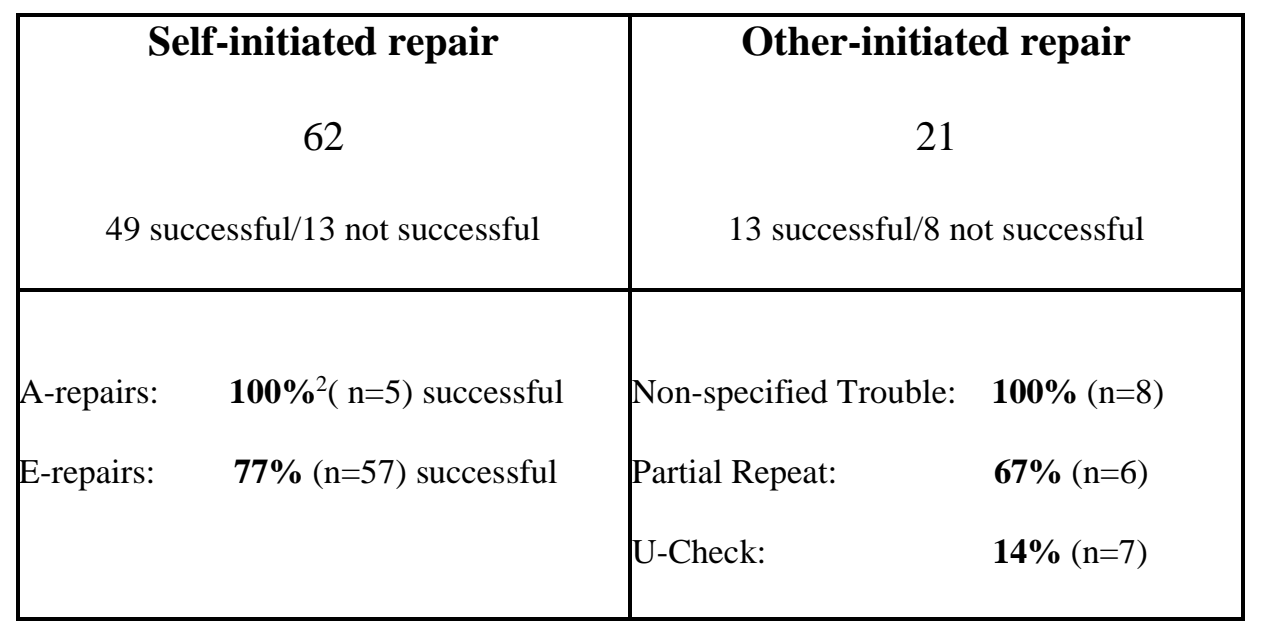

Table 1: Level of success in relation to the form of repair

\footnotetext{
${ }^{2}$ Although the number of instances does not allow for statistical analysis, the percentages are given in this section to facilitate the discussion. Visual aids would have been possible but would only support the presentation when using percentages due to the number of aspects that are being compared. Otherwise, the explanation of the chart would not be in a reasonable relation to its purpose.
} 
In the next chart, the successful repair will be presented in relation to the three different learner groups, i.e. how successful were very, moderately and less successful learners overall in terms of the two major self-repair types.

\begin{tabular}{|l|c|c|}
\hline Degree of Previous & Self-initiated & Other-initiated \\
& self-repair & self-repair \\
$\mathbf{n}=\mathbf{6 2}$ & $\mathbf{n}=\mathbf{2 1}$ \\
\hline & $\mathbf{8 9 \%}(\mathrm{n}=9)$ & $\mathbf{6 0 \%}(\mathrm{n}=5)$ \\
Very & $\mathbf{8 7 \%}(\mathrm{n}=38)$ & $\mathbf{8 3 \%}(\mathrm{n}=6)$ \\
Moderately & $\mathbf{5 3 \%}(\mathrm{n}=15)$ & $\mathbf{5 0 \%}(\mathrm{n}=10)$ \\
\hline
\end{tabular}

Table 2: Level of success in relation to the form of repair

The chart shows that the moderately successful learners achieve the highest degree of overall correctness/appropriateness in terms of repair, very successful learners are slightly more successful in self-repair but clearly less so in terms of other-initiated repair where only three out of five instances were repaired with modified output. Less successful learners repair approximately half of their trouble sources successfully.

The following chart relates success to both, the degree of success of the learner and to the type of repair, i.e. it becomes obvious which type of repair results in the highest success for each learner group. These findings may be of relevance for (pedagogical) implications of this study, which are discussed in the final section. 


\begin{tabular}{|l|c|c|c|}
\hline & \multicolumn{1}{|l|}{$\begin{array}{l}\text { Very } \\
\text { Successful }\end{array}$} & successful & \\
\hline Error-Repair & $\mathbf{8 8 \%}(\mathrm{n}=8)$ & $\mathbf{8 5 \%}(\mathrm{n}=34)$ & $\mathbf{5 3 \%}(\mathrm{n}=15)$ \\
A-Repair & $\mathbf{1 0 0 \%}(\mathrm{n}=1)$ & $\mathbf{1 0 0 \%}(\mathrm{n}=4)$ & N/A \\
\hline P-Repeat & $\mathbf{5 0 \%}(\mathrm{n}=2)$ & $\mathbf{6 7 \%}(\mathrm{n}=3)$ & $\mathbf{1 0 0 \%}(\mathrm{n}=1)$ \\
U-Check & $\mathbf{3 3 \%}(\mathrm{n}=3)$ & N/A & $\mathbf{0 \%}(\mathrm{n}=4)$ \\
U-Trouble & N/A & $\mathbf{1 0 0 \%}(\mathrm{n}=3)$ & $\mathbf{1 0 0 \%}(\mathrm{n}=5)$ \\
\hline
\end{tabular}

Table 3: Level of success in relation to the form of repair and the three different student groups

The chart shows that there is a huge gap between the achievement of the moderately and very and the less successful students in terms of error repair. A-repair only occurs among very and moderately successful students and is repaired successfully in all cases. Overall, less successful students achieve a higher degree of correctness when the repair is other-initiated, i.e. when the instructor initiates the repair. With the exception of the understanding-check, all other forms of other-initiated repair were done appropriately/correctly. The very successful students turn out to have the lowest achievement with respect to other-initiated repair.

\section{Discussion}

Overall, it turned out that moderately successful students showed by far the most instances of selfrepair, which is assumed to be attributed to the following facts: Naturally, very successful students show less trouble sources and, therefore, need to repair less frequently. Less successful students do make mistakes but their low linguistic awareness results in a rather less frequent identification of trouble sources which results in an overall lower number of repair instances. Moderately 
successful students do have a relatively high number of trouble sources but they also have the necessary linguistic awareness to spot them and to repair them successfully rather frequently. It is interesting to see that overall, moderately successful students were more successful in terms of repair than very successful students who are also assumed to have a high degree of linguistic awareness. The higher level of success among moderately successful students may be based on attention and the self-perception of one's own linguistic skills. While very successful students may not see the necessity to paying attention to potential trouble sources due to their self-perception as a successful learner, this might be due to the fact that they are less trained to repair than moderately successful students are. They are at the same time less used to making mistakes and thus to eliciting instances that are repair worthy. Moderately successful students in turn know that they are prone to making mistakes and thus pay more attention or monitor their speech to a higher degree and are more used to repair self- or other-initiated instances. The fact that very successful students repair only slightly more than half of the instances of other-initiated repair successfully (and thereby only slightly more successful than less successful students), whereas moderately students repair five out of six successfully, might indicate that very successful students are not used to repair and therefore are not trained to react appropriately. In the case of the less successful students the low number of successful repairs is probably due to the lacking linguistic awareness or competence to sport and fix the trouble source. More qualitative research is needed to verify these observations and interpretations.

The setting of an oral exam, i.e. an assessment environment, makes the students even more aware of their own achievement as he/she is tested in exactly these terms, i.e. the learners seem to be very well aware of their competences, especially very and moderately successful students. As a consequence, very successful students rely on their ability 'too much' whereas moderately 
students use their awareness of deficits as a source for monitoring their speech, spotting trouble sources and, as a consequence, repair them successfully. In terms of the dichotomy self vs. other and the implied hierarchy might be of relevance for the very and the moderately successful students.

As had been assumed, the vast majority of repairs are self-initiated self-repairs, which can be seen as a consequence of the oral exam setting, which does not allow for too much intervention of the instructor. It turned out to be true that self-initiated repair results in a higher amount of output modification than is the case for other-initiated repair which is seen as an indicator of successful repair. However, it has to be taken into account that the nature of the repair form may be responsible for the lacking modification of output, i.e. if other-initiated repairs can be answered with yes or no or by non-verbal gestures, there is no communicative need to modify the output. Hence, the success of the repair could be measured more reliably by analysing potential occurrences of the same form within the course of the conversation to see if they are formed correctly in a future turn (if applicable). Consequently, it has to be differentiated between communicative success of other-initiated repair, i.e. following conversational rules and keeping the conversation flow (as is being achieved by reacting with yes/no) and success in terms of foreign language learning, i.e. will the correct form actually be used in the future. It was further hypothesized that error repairs will be the dominant form, which clearly turned out to be true. Only five instances of a-repair could be observed and the fact that they only occurred among very and moderately successful students indicates that the overall low proficiency level can be identified as the reason for the dominance of the error repairs as students do not have enough linguistic flexibility yet which would allow for other forms of repair to occur that focus less on linguistic accuracy. 
For the formulation of expected results in terms of other-initiated repair, McHoul's findings that the teacher tries to initiate repair by cluing serves as a frame of reference here. Out of 21 instances of other-initiated repair, 15 were covered by non-specified trouble or understanding checks which can both be seen as rather unspecific, 'open' forms which allow for the 'freedom' as had been observed by McHoul. However, the findings here indicate that the freedom is given to the students but afterwards, no small steps are provided to further specify the trouble source probably due to the assessment setting. However, as all instances of non-specified trouble were repaired successfully, these small steps were clearly not necessary. In the case of the U-check, which was only successful once among seven instances those steps would have been necessary but were not further pursued. Apparently, students can deal better with the other indicating that something is wrong with the message so that they can decide themselves whether the trouble source is meaning- or accuracy related whereas the U-check usually indicates whether the trouble source refers to content or accuracy. These findings are rather surprising given the success of scaffolding or cueing that has been discussed before. For that reason, it was assumed that U-checks would have been more successful by giving the students a direction for their repair. However, U-checks provide even more input in the foreign language, which has to be processed. Thus, they offer even more potential trouble sources, especially in a setting of assessment where it can be assumed that students are very nervous. The fact that the less sufficient students have no single instance of successful repair with respect to U-checks whereas very successful students have at least one out of three supports this view. It can be concluded that the indication that something is wrong creates less pressure in the student by giving him/her more time to think about their own utterance instead of focusing on other-initiated repair forms that need to be processed to and related to one's own utterance. In 'ordinary' classroom settings, this pressure is assumed to be lower due to the less 
dominant power relations between student and instructor and the less concentrated focus on assessment.

Within this context, it further has to be noted, however, that the oral exam situation in general leaves less room for the other to initiate repair as it is 1. not appropriate for the setting and 2. would even reduce the student's chance to achieve a good performance as too much time would be spent to initiate successful repair, which can be seen as a major difference between classroom and oral exam settings. While classroom repair usually aims at the improvement of students' foreign language skills or at the negotiation of meaning for conversational purposes, the other in oral exam settings uses repair to achieve (mutual) understanding which serves as a basis for assessment.

The structure of the trouble sources was, as could be assumed, predominantly grammatical which is true for all three student groups, which is attributed mainly to the fact that the overall proficiency of the learners was very low.

\section{Conclusion and Pedagogical Implications}

As can be seen, many findings of studies that were conducted in the foreign language in terms of self-repair can be applied to the setting of an oral exam. Yet, there are numerous major differences between these two settings. The repair-related idiosyncrasies in oral exams are summarized as follows:

a) In oral exam situations, the purpose of other-initiated repair is predominantly to achieve (mutual) understanding and clarification for the instructor, i.e. ensuring that the utterances are understood correctly, be it content or language wise. This is necessary in order to 
achieve an adequate setting for assessment, which can be seen as economic or pragmatic (in the literal sense) reasons whereas in classroom settings, repair is either used to improve language proficiency or to negotiate meaning for conversational purposes. Consequently, the complementary or asymmetric nature of the student-instructor relationship also finds its manifestation in the purpose of repair. In everyday classroom settings, this purpose or function of repair is not known to the students because the self-other dichotomy is less stressed in that context and repair usually serves the functions as described above.

b) In general, other-initiated repair can be an impediment in terms of the students' performance in the oral exam setting as it is rather uneconomic and reduces the chances of producing more output which then serves as the basis for assessment.

c) U-checks seem to be a rather problematic form of other-initiated repair for the oral exam setting, for the reasons mentioned in a) and due to the higher degree of stress and nervousness which may serve as an additional trouble source, especially for less successful students. Unspecified trouble indications seem to leave enough room for the student to focus on their own utterance instead of processing more input from the instructor and connecting it with their own.

d) The assessment setting may lead to a stronger focus on the self-perception of one's own skills which is beneficial for moderately successful students but can be considered as an impediment for very successful learners. 
e) The functions of repair in everyday classroom settings seem to train the students to deal with repair in a way that is very different from assessment situations because it serves different purposes

With respect to conclusion a) it would be interesting to find out whether the degree of mutuality is as high as in the classroom setting or whether it is more important for the instructor, the other, to make sure that the students' output is understood properly to ensure assessment which is as valid as possible. Furthermore, it would be interesting to compare findings of this study with studies that focus on a symmetrical relationship, i.e. exams within which students communicate with each other.

Also, it would have been insightful to distinguish more precisely between forms of otherinitiated repair that are to achieve mutual understanding and those that cover error repairs, i.e. in addition to Schegloff's model a presentation of the findings in terms of the two categories mentioned above.

During the design of the study, it was decided to leave out instances of covert repair as they cannot be directly spotted but rather need to be derived from hints like repetitions, pauses etc. It turned out, however, that there were many instances of clearly identifiable covert repair which may offer valuable insights into the learner's process of repair as some of them showed very detailed instances of 'thinking aloud'. Within this context, a closer look at body language during the thinking-aloud process may offer even more interesting perspectives. These findings could also shed light on linguistic reasoning with respect to native English learners of German. In relation to this, the investigation of the different turns in which repair occurs may be yet another valuable resource for the underlying processes of self-repair. 
In addition to these suggestions for further research, the term of success could be approached from a different perspective. Instead of measuring success by the number of trouble sources that were repaired successfully in relation to the overall number of repairs, it may be interesting to measure success, and thereby the level of attention or monitoring, by spotting trouble sources which had not been identified by the students and relate those to the number of sources that were actually identified (and successfully repaired).

Based on the findings above, pedagogical implications can be formulated.

One major implication from this study is definitely based on the findings for very successful students which seem to call for a higher confrontation with other-initiated repair. Although very successful students already do have the highest possible mark, further research could reveal interesting findings on whether or not their overall proficiency could be improved even more by training them how to repair.

As other-initiated repair is a frequent phenomenon in authentic speech with speakers of the target language, it should be taught explicitly as a strategic device, including the use of body language to initiate repair and maybe even as a means to achieve successful repair. Especially understanding checks seem to be troublesome which may lead to the implication that listening skills in general and the processing of meta-conversational information (which may be a U-check) should be trained to a higher extend in classroom settings. In the setting of an oral exam, the students were confronted with a function of repair that they are not familiar with from their classroom experience, i.e. a pragmatic function of repairs that they do not seem to be ready to respond to in the target language. Some of these functions are related to the dichotomy self versus other. While everyday classroom settings distance themselves more and more from this dichotomy 
and conceptualize the teacher as a coach or assistant, new forms of assessment might become necessary in order to avoid the trouble related to this discrepancy. 


\section{Works Cited}

Brandl, Klaus. Communicative Language Teaching in Action: Putting Principles to Work. Pearson, 2008.

Dippold, Dieter. "That's Wrong: Repair and Rapport in Culturally Diverse Higher Education Classrooms.” The Modern Language Journal, vol. 98, no. 1, 2014, pp. 402-16.

Egbert, Maria "Context-Sensitivity in Conversation: Eye Gaze and the German Repair Initiator bitte?" Language in Society, vol. 25, 1996, pp. 587-612.

—. "Miscommunication in Language Proficiency Interviews of First-Year German Students: A Comparison with Natural Conversation." Discourse Approaches to the Assessment of Oral Proficiency. Edited by R. Young and A. Weiyun He. John Benjamins, 1998, pp. $147-69$.

Fathman, Ann. "Repetition and Correction as an Indication of Speech Planning and Execution Processes Among Second Language Learners." Towards a Crosslinguistic Assessment of Speech Production. Edited by H. Dechert, and M. Raupach. Lang, 1980, pp. 77-85.

Filipi, Anna. "Interaction in an Italian Oral Test: The Role of some Expansion Sequences." Australian Review of Applied Linguistics, vol. 11, 1994, pp. 119-36.

Gass, Susan. "Input and Interaction." The Handbook of Second Language Acquisition. Edited by C.J. Doughty and M.H. Long. Blackwell, 2000, pp. 224-55.

Jung, Euen H. "The Organization of Second Language Classroom Repair." Issues in Applied Linguistics, vol. 10, no. 2, 1999, pp. 153-71.

Kormos, Judit. "Monitoring and Self-Repair in L2." Language Learning, vol. 49, no.2, 1999, pp. $303-42$. 
—. "The Role of Attention in Monitoring Second Language Speech Production". Language Learning. Vol. 50, 2000, pp. 343-84.

Krashen, Stephen. The Input Hypothesis: Issues and Implications. Longman, 1985.

Lennon, Paul. "Investigating Fluency in EFL: A Quantitative Approach.” Language Learning, vol. 40, 1990, pp. 387-417.

Levelt, Willem. "Monitoring and Self-Repair in Speech." Cognition, vol. 14, no.1, 1983, pp. 41104.

Liebscher, Grit and Jennifer Dailey-O’Cain. “Conversational Repair as a Role-Defining Mechanism in Classroom Interaction.” The Modern Language Journal, vol. 87, no. iii, 2003, pp. 375-90.

Lightbown, Patsy. "Input and Acquisition for Second-Language Learners in and Out of Classrooms." Applied Linguistics, vol. 6, no. 3, 1985, pp. 263-73.

McHoul, Alec "The Organization of Repair in Classroom Talk." Language in Society, vol. 19, 1990, pp. 349-77.

Nakamura, Ian. "Understanding How Teacher and Student Talk with Each Other: An Exploration of How 'repair' Displays the Co-Management of Talk-in-Interaction." Language Teaching Research, vol. 12, no. 2, 2008, pp. 265-83.

Pica, Teresa and Gay Washburn. "Negative Evidence in Language Classroom Activities: A Study of its Availability and Accessibility to Language Learners." Working Papers in Educational Linguistics, vol. 18, no.1, 2002, pp. 1-28.

Razfar, Aria. "Language Ideologies in Practice: Repair and Classroom Discourse." Linguistics and Education, vol. 16, no. 4, 2005, pp. 404-24. 
Rylander, John. "Interaction in Chinese as a Foreign Language Classroom: A Conversation Analysis Approach.” Second Language Studies, vol. 23, no. 1, 2004, pp. 67-144.

Sacks, Harvey, Schegloff, Emanuel A., and Jefferson, Gail. "A Simplest Systematics for the Organization of Turn-taking for Conversation." Language, vol. 50, 1974, pp. 696-735.

Schegloff, Emanuel, Harvey Sacks, and Gail Jefferson. "The Preference for Self-Correction in the Organization of Repair in Conversation." Language, vol. 53, no.2, 1977, pp. 361-82.

Schegloff, Emanuel. “When 'Others’ Initiate Repair.” Applied Linguistics, vol. 21, no.2, 2000, pp. 205-43.

Selting, Margaret, et al. "Gesprächsanalytisches Transkriptionssystem 2 (GAT 2)."

Gesprächsforschung. Online-Zeitschrift zur verbalen Interaktion, vol. 10, 2009, pp. 353402.

Simpson, Rebecca, Eisenchlas, Susana, and Michael Haugh. "The Functions of Self-initiated SelfRepair in the Second Language Chinese Classroom". International Journal of Applied Linguistics, vol. 23, no. 2, 2013, pp. 144-65.

Smith, Bryan. "Methodological Hurdles in Capturing CMC Data: The Case of the Missing Selfrepair." Language Learning \& Technology, vol. 12, no.1, 2009, pp. 85-103.

Swain, Merrill. “Communicative Competence: Some Roles of Comprehensible Input and Comprehensible Output in Its Development." Input in Second Language Acquisition. Edited by S. M. Gass and C. G. Madden. Newbury House, 1985, pp. 235-53.

Tang, Chihsia. "Self-Repair Devices in Classroom Monologue Discourse." Concentric: Studies in Linguistics, vol. 37, no. 1, 2011, pp. 93-120.

van Hest, Erna, Polisse, Nanda, and Theo Bongaerts. Self-repair in L1 and L2 Production. Tilburg UP, 1996. 
van Lier, Leo. The Classroom and the Language Learner. Longman, 1988.

Vygotski, Lev. Denken und Sprechen. Edited by Johannes Helm with an Introduction by Thomas Luckmann. Fischer, 1977.

Watzlawick, Paul. Menschliche Kommunikation - Formen, Stoerungen, Paradoxien. Huber, 1969/2011.

\section{Image Notes}

All charts and tables were created by the author.

Chart 1: Forms of self-initiated repair according to Levelt

Chart 2: Distribution of self-initiated self-repair amongst learners with a different degree of language learning success

Chart 3: Forms of other-initiated self-repair according to Schegloff et al.

Chart 4: Distribution of other-initiated self-repair amongst learners with a different degree of language learning success

Table 1: Level of success in relation to the form of repair

Table 2: Level of success in relation to the form of repair and the three different student groups 